\title{
La ausencia del cuerpo y el sujeto político en los webdocumentales de Sharon Daniel
}

\author{
Diego Zavala \\ Realizador, Docente e Investigador \\ (Tecnológico de Monterrey)
}

\section{Referencia de este artículo}

Zavala, Diego (2020). La ausencia del cuerpo y el sujeto político en los webdocumentales de Sharon Daniel. adComunica. Revista Científica del Estrategias, Tendencias e Innovación en Comunicación, (19), 275-290. DOI: http://dx.doi. org/10.6035/2174-0992.2020.19.15.

\section{Introducción}

El presente texto es un devenir, es el paso de una forma de mirar el documental como algo sujeto a una materialidad ineludible, hacia una visión más abstracta y compleja de la relación entre la filmación y la realidad. Es el paso a la inclusión de mecanismos representacionales no realistas dentro del cine de no ficción. Este trance puede ser definido, sinecdóquicamente, como el salto de la postura nicholsiana clásica presente en su libro canónico, La representación de la realidad, a la perspectiva de Jean-Louis Comolli en un brevísimo artículo de su libro Ver y poder, titulado Cine documental y cuerpo político. Este salto teórico, que luego explicaré a detalle, es lo que motiva la generación de un análisis multimodal de dos de los webdocumentales de Sharon Daniel, Public Secrets y Blood Sugar donde esta transición es evidente.

El interés del análisis es revisar qué dispositivos, elementos o componentes de la forma documental, en general, y de la forma interactiva, en particular, utilizan estas dos piezas para reflexionar sobre la condición política de los temas que aborda. Su formulación estética y funcional dan cuenta del cambio de perspectiva 
en el que la materialidad y el nexo indicativo son diluidos con una intención de crítica social clara, pero que al nivel narrativo funciona justo como un énfasis en las ideas o conceptos que los sujetos aportan, transformando la presencia física de las personas en otra forma de testimonio.

Esta revisión de los casos lo que nos permitirá es perfilar algunas de las tendencias de la forma documental interactiva en el trabajo de Sharon Daniel, así como su utilidad para pensar la condición política en tiempos de la convergencia digital, la vigilancia y la auto vigilancia audiovisual (Bakir, 2010) para, al final, argumentar cómo es que estas piezas abonan a la construcción de una cultura legal (Silbey, 2010) vinculada al mundo de las imágenes, los sonidos y, ahora, también de la interactividad artística, que involucra la representación de la realidad. Lo que deriva en una expansión que cuestiona y critica la visión simplista del documental como forma próxima a la reproducción no mediada, naturalizada de la realidad.

\section{El trabajo de Sharon Daniel}

Sharon Daniel es una artista digital americana, creadora de piezas documentales interactivas y participativas, con las que aborda temas de injusticia social, racial y ambiental, con un particular énfasis en el encarcelamiento masivo y el sistema de justicia criminal. Sus trabajos suelen buscar mecanismos de participación en el arte basado en internet; o bien crea nuevas formas documentales que se expanden hacia instalaciones a través de interfaces físicas y piezas museográficas. Su labor creadora ha sido expuesta internacionalmente en galerías y museos, así como en los grandes festivales de cine documental y documental interactivo ${ }^{1}$.

Su trabajo artístico es complementado por su actividad docente en la Universidad de California, Santa Cruz. Este contexto académico de producción también ha promovido que ella misma escriba sobre su trabajo en revistas científicas como Vectors, Cinema Journal, Leonardo y Studies in Documentary Film. También ha sido acreedora de premios como el Webby, y ha sido apoyada en su trabajo por los fondos Fullbright, Tribeca y Rockefeller.

De entre toda la producción de Daniel nos centraremos en dos piezas para el presente análisis: Public Secrets y Blood Sugar. La primera aborda las injusticias del complejo industrial de prisiones, considerándolas como secretos públicos. La pieza proporciona una interfaz interactiva de un archivo de audio de cientos de declaraciones hechas por mujeres encarceladas que desenmascaran injusticias secretas de la guerra contra las drogas, el sistema de justicia criminal y la industrialización del negocio carcelario. Los visitantes navegan una narrativa multivocal que vincula

\footnotetext{
1 Algunas de sus exhibiciones han sucedido en la sección Alternate Realities del festival de Sheffield Doc|Fest (Reino Unido, 2016), una exposición en solitario en Convictions en el STUK Kunstencentrum, (Bélgica, 2013) en la bienal de arte WRO en 2011 (Polonia), Artefact 2010 (Bélgica), Transmediale 08 (Alemania), en el Dutch Electronic Arts Festival DEAF03 (Holanda), Ars Electronica (Austria), y en el Lincoln Center Festival (NY/USA).
} 
el testimonio individual con evidencia pública; la teoría social con afirmaciones personales, en un esfuerzo por involucrar al público en un diálogo crítico sobre el crimen y el castigo, así como retar la suposición de que el encarcelamiento provee soluciones a problemas sociales.

La segunda pieza examina la construcción social y política de la pobreza y la adicción en la sociedad americana, a través de los ojos de aquellos que viven con ellas. Porque los adictos en los Estados Unidos temen los encuentros con los regímenes de control así como ser detectados por ellos, estar bajo la lupa; pero, al mismo tiempo, quieren ser escuchados. Sus voces son las más importantes en el discurso sobre la adicción, la salud pública y la pobreza en Estados Unidos. Blood Sugar provee una interfaz interactiva a un archivo de audio con conversaciones con veinte consumidores y ex consumidores de drogas intravenosas, grabadas en el Programa de educación y prevención del VIH en el Condado de Alameda, así como en prisiones estatales de California. En este webdocumental, los visitantes navegan por una narrativa multivocal que vincula el testimonio individual y la evidencia pública, la teoría social y la investigación biológica ${ }^{2}$.

Aunque Daniel no rehúye el uso del cuadro de entrevista, o la grabación del cuerpo del entrevistado, sí es una constante en su trabajo problematizar el registro directo de la imagen y el sonido de sus colaboradores e informantes. Esta particularidad, presente en los dos trabajos que analizamos (así como en otros), le permite decidir elementos relevantes sobre lo que se ve y se registra. Estos modos de formalización, que pueden servir como una forma de dar anonimato a las personas para evitar justo la victimización o persecución de los individuos por su participación, hasta una manera de desdibujar la obsesión del individuo como fuente de certidumbre informativa para convertir las voces en un coro, en una comunidad que interpele al espectador-navegador. Ambos extremos emergen en las piezas seleccionadas con implicaciones políticas claras, y por ello nos parece que es necesario explorarlas y caracterizarlas.

\section{Horizonte teórico para pensar lo político en el documental y el webdocumental}

Antes de pasar a la caracterización detallada de las piezas y sus formalizaciones expresivas específicas, es importante completar el campo teórico general donde la discusión sobre el uso de recursos no realistas de representación se vuelve fértil. Para ello, retomo y profundizo sobre el replanteamiento al que nos referíamos al inicio del texto. La obra de Daniel pretende ayudarnos a evidenciar cómo es que funciona el nexo indicativo del cine de no ficción (y en particular la forma interactiva) para pensar la relación del documental con la realidad desde otro espacio

2 Ambas sinopsis son traducciones al castellano de la información encontrada en la página personal de Sharon Daniel: sharondaniel.net 
teórico que, de algún modo pone en jaque algunos de los bastiones de la teoría de estas formas cinematográficas y sus expansiones. Podríamos formularlo como una puesta en duda del cuerpo como principio de la relación entre realidad y su representación; así como del vínculo entre el realismo y el cine documental.

El planteamiento general de la importancia del cuerpo, y por ende de la imagen, en el documental se suele asociar con el canon de la teoría documental que durante mucho tiempo fue el trabajo de Bill Nichols. Y que para efectos de este trabajo, podemos sintetizar con uno de los pasajes del capítulo 8 de su libro clásico, La representación de la realidad. En él, el autor americano señala que:

«el cine documental hace hincapié en la presencia del cuerpo. Ejerce una demanda incesante de habeas corpus. Al igual que el sistema legal, el discurso documental hace hincapié en el principio de que se nos debe presentar el cadáver. Testigo y testimonio, exposición y refutación, acusación y negación: todo ello depende del enfrentamiento directo y la presencia física» (1997: 293).

Y justo a esta noción general o principio normativo de la forma documental oponíamos, de manera general, el pensamiento del teórico francés, Jean-Louis Comolli que expresaría en uno de sus artículos que:

«...en lo que hace al compromiso del cuerpo y de la palabra, al mismo tiempo que en cuanto a actos e ideas. Documental o no, el cine filma, primero, cuerpos, y si se trata de palabras, de pensamientos, de principios, los filma encarnados. No es seguro, en ese sentido, que el cine no haya modificado profundamente la naturaleza de la relación política. Y es justamente por eso que a partir del cine directo y el sonido sincrónico, ya no vaya tanto hacia el cuerpo, ya no ponga el acento en él, sino que se dirija hacia las ideas o los principios» (2007: 285-286).

No hay que perder de vista que tanto el cuerpo como principio de la indexación documental y, por ende, su vocacionamiento directo, casi instantáneo hacia una representación realista han sido evadidos, criticados, suspendidos, expandidos y cuestionados por el cine experimental. El arte no figurativo, las formas abstractas, la poética visual, el ritmo de las imágenes en el cine son este espacio donde el reconocimiento de las formas, la perspectiva y la proporción no son los conceptos rectores de estas piezas fílmicas. Pero cuando hablamos de documental vinculado a una perspectiva de justicia social o visión política, es poco común encontrar formas de no ficción que mantengan una perspectiva estética no realista y aun así tengan un punto de vista crítico sobre algún evento o proceso histórico. Casi siempre la dislocación del documental con el arte deriva en que a las piezas cuya representación de la realidad no sea realista se le denomine como cine artístico o experimental y que su función de crítica social o visión política sea vista como algo secundario. Es por ello que el trabajo de Daniel se presenta como singular y apto para el análisis.

Este antecedente claro nos marca un territorio de exploración de las filiaciones del trabajo de Sharon Daniel que analizamos en este texto. El cine experimental, 
el video arte y el arte digital son fuentes naturales de las que abreva su apuesta material. Lo que pretendo explicar es cómo esta forma de realización también se basa en una decisión y postura políticas. Al tiempo que plantea el desdibujamiento del cuerpo y la presencia de la persona frente a la cámara como una distancia crítica y moral del dispositivo fílmico, hace eco del cine experimental abstracto. Con ello, lo que logra es generar una ausencia evidente de un elemento central del mecanismo de representación para problematizarlo, descomponerlo y reactivarlo con fines narrativos, estéticos y reflexivos.

Daniel explica, en uno de sus textos, este intento de maridaje, mezcla de ambos procesos que durante épocas y en varios movimientos documentales han estado separados. Dice, además citando a Jacques Rancière que:

\footnotetext{
«arte y política, cada uno define una forma de disenso [...] si existe algo así como una 'estética de la política', reside en la reconfiguración de la distribución de lo común a través de procesos políticos de subjetivación. [...] La 'estética de la política' consiste por encima de todo en enmarcar un nosotros, un sujeto, una demostración colectiva cuya emergencia es el elemento que interrumpe la distribución de las partes sociales, un elemento que yo llamo la parte de aquellos que no tienen parte» (Rancière citado en Daniel, 2012: 216).
}

Esta forma de argumentación lo que reconoce es la importancia de los sujetos pero a través de la emergencia de la colectividad y como un proceso de enmarcamiento que permite una reconfiguración, que también podríamos denominar como dislocamiento o expansión de la pieza artística para incorporar la dimensión política. Esta forma de documental de base abstracta en su formulación visual tiene una vocación clara de generar esta discusión y asumirse como una forma de conjunción de las dos formas de disenso, la del arte y la de la política. Esta es la conjunción que nos interesa explicar a partir de las partes que componen los documentales interactivos seleccionados y ver cómo es que opera esta búsqueda de la creación de una perspectiva colectiva como principio político.

Este camino de adscripciones y negaciones formales es la secuencia que siguen los trabajos para ser decodificados y permitir al espectador-interactor hacer una inmersión en el universo que Daniel ha creado para nosotros. A medio camino entre una experiencia sensorial y cognitiva, que nos demanda evadir la presencia corporal y visual de quien brinda el testimonio para forzarnos lejos del camino directo de la naturalización discursiva y realista en el que voz y cuerpo van unidos. Es así como nos entregamos al territorio de la sospecha, de la construcción visual de las voces por sustitución de elementos presentes y que derivan en la dislocación de los cuerpos individuales, el aseguramiento del anonimato de los participantes y la construcción de un cuerpo político conformado por un coro de voces y nubes de gráficos textuales que nos ayudan a completar la experiencia donde de las múltiples opiniones y testimonios, a partir de la colectividad de vivencias, nosotros extraemos sentido y conocimiento en un ambiente creado para una vivencia individualizada que nos interpela sobre nuestra posición, nuestra distancia, nuestro 
cuerpo y nuestra voz. A continuación presentamos un desglose sistematizado de estos componentes desde un modelo de análisis multimodal para explicar las partes e interacciones que nos permiten hacer esta descripción del trabajo de Daniel.

\section{Categorización y análisis, primeras intuiciones sobre el testimonio y la comunidad}

Como hemos señalado anteriormente, Sharon Daniel utiliza en ambos casos la herramienta de la entrevista para conformar la base de datos, el compilado de declaraciones que conformarán las piezas que analizamos. Por lo tanto, podemos decir que el testimonio será una categoría fundamental para cuestionar su trabajo, igual que lo fue para conformarlo. El testimonio, por tanto, será el principio del eje de análisis y, como menciona Daniel en sus escritos, el punto de llegada es, en el otro extremo del eje: la comunidad. Esa es la idea, conectar los comentarios individuales para revelar el nosotros al que se refería Rancière.

Esbozando brevemente este concepto podemos afirmar que:

«presenciar y dar testimonio provee marcos teóricos útiles para entender el trabajo de los filmes como productores de información y transformación en las audiencias. Históricamente entendidos como narraciones verdaderas, en primera persona, sobre el sufrimiento, hechas para transformar el mundo, el testimonio se relaciona a los esfuerzos retóricos de proyectos fílmicos que retratan atrocidades distantes con la intención de terminarlas. El término es asociado más comúnmente con los tribunales donde los testigos jurados declaran sobre un caso para lograr justicia» (Torchin, 2012: 5) .

Esta búsqueda de la justicia es la función precisa que el trabajo de Sharon Daniel intenta recuperar a través de los testimonios de personas encarceladas o drogodependientes. Por eso es tan relevante la forma de presentar estas declaraciones, de acercarnos a esas historias. Pero la artista, además es consciente de que el propio mecanismo del registro expande y redimensiona el testimonio, por eso también modifica las grabaciones, dislocando la imagen, para hacernos pensar sobre esta modificación generada por la mediación. En palabras de Torchin podríamos argumentar que:

\footnotetext{
«mejorando radicalmente el encuentro testimonial, la presencia mediática trabaja en tres sentidos. Paul Frosh y Amit Pinchevski describen esta función tripartita como presenciar en, por y a través de los medios. Esto es que los testigos pueden ser vistos en pantalla; medios (periodistas, video amateurs) pueden atestiguar eventos; y las audiencias se pueden volver testigos a través de mirar las pantallas» (Torchin, 2012: 7).
}

El mejoramiento señalado por Torchin es también susceptible de duda y sospecha. El registro naturalizado puede volver invisible el dispositivo de registro y hacer parecer que no hay relaciones de poder en la construcción mediática de lo filmado. La microfísica del poder ejercida en la performatividad documental (como lo denominara Stella Bruzzi, 2016) pueden ocultarse o ser desbordadas por la potencia de 
los eventos o argumentos filmados. Así lo expresa Jessica Silbey, investigadora de las relaciones entre la imagen fílmica y la ley, y que nos puede ayudar a entender mejor el mecanismo utilizado en los dos documentales web y que luego constataremos con el análisis multimodal. Silbey explica que:

\footnotetext{
«Cada vez más, este tipo de evidencia verité 3/4registros de arrestos, confesiones criminales y de escenas de crímenes ${ }^{3 / 4}$ es rutinariamente admitida en las cortes legales de Estados Unidos como la mejor evidencia de lo que pasó. Este tipo de evidencia tiende a abrumar al resto, tales como las declaraciones de testigos, registros en papel y otra evidencia documental. La evidencia verité también tiende a ser inmune al análisis crítico. Es rara vez analizada por su ambigüedad, sus tendencias o sus incompletitudes. Por el contrario, es muy usualmente admitida sin ninguna examinación cruzada en absoluto» (Silbey, 2010: 1257-1258).
}

Daniel desactiva el mecanismo de la vigilancia, de lo que Silbey y Bruzzi denominan evidencia verité, la ubicuidad del registro audiovisual del preso, el juzgado, el detenido, donde la cámara se ha vuelto el panóptico foucaultiano para obligarnos a no mirar, para poder observar con detenimiento el fenómeno y poder ingresar, no a través de nuestros ojos, sino de nuestros pensamientos y prejuicios. La desactivación del dispositivo del directo videográfico eterno de la cámara de vigilancia es la activación del dispositivo interactivo-inmersivo usado por la artista.

\section{Modelo de análisis multimodal y su implementación a los casos seleccionados}

Ante la complejidad formal del arte interactivo y sus múltiples modos de producción de sentido, consideramos que un análisis multimodal es uno de los mecanismos ideales para cuestionar su funcionamiento, intenciones y alcances. Esta expansión de las teorías de la semiótica social y los estudios de medios de comunicación, como puede revisarse en Bateman, Wildfeuer e Hiipala (2017) y en Kress (2010) sirven de base metodológica para abordar las piezas del presente trabajo. Particularmente útil encontramos el modelo propuesto por Luc Pauwels (2011) que específicamente se centra en aplicarlo a sitios web, a los que entiende como expresiones socioculturales. Y para efecto del arte de base web, como los trabajos de Sharon Daniel, nos parece idóneo.

A continuación presentamos un índice de los siete momentos o fases, y sus subfases, del modelo propuesto por Pauwels para, posteriormente, aplicarlo a los documentales web que analizamos. Hacemos notar que para un desarrollo completo del modelo, particularmente el análisis de contenido en profundidad, haría falta un trabajo mucho más extenso, que excede los alcances del presente artículo. También podemos avanzar que, para este análisis, el punto número dos resulta especialmente significativo y donde encontramos el basamento de nuestra argumentación que, posteriormente se podría desglosar más a detalle si se hiciera un análisis de contenido exhaustivo y sistemático. De momento, los elementos arrojados en el 
inventario son suficientes para sostener lo aquí explicado y arribar a las conclusiones que hemos perfilado desde el inicio. No necesitamos descender hasta la descripción específica de cada elemento para rescatar los tópicos, los modos de inserción de los testimonios y cómo ellos abonan a pensar en una comunidad con una visión política sobre los tópicos planteados.

El índice propuesto por Pauwels es el siguiente:

1. Preservación de las primeras impresiones y reacciones

1.1. Categorización de cómo se ve y siente a primera vista

1.2. Grabación de reacciones afectivas

2. Inventario de características sobresalientes y tópicos

2.1. Inventario de elementos y atributos presentes en el sitio web

2.2. Inventario de las principales categorías de contenido y tópicos

2.3. Categorización y cuantificación de elementos y tópicos

2.4. Hacer análisis negativo: elementos y tópicos significativos ausentes

3. Análisis de contenido en profundidad y decisiones formales

3.1. Análisis intramodal (elementos fijos, estáticos, dinámicos y en movimiento)

3.1.1. Significantes verbales y escritos

3.1.2. Significantes tipográficos

3.1.3. Significantes y tipos de representaciones visuales

3.1.4. Significantes y tipos de sonido

3.1.5. Significantes de diseño y distribución de la web

3.2. Análisis e interacción de cruces modales

3.2.1. Relaciones de imagen y texto escrito y de texto escrito y tipografías

3.2.2. Relaciones entre sonido e imagen

3.2.3. Interacciones generales de diseño, elementos lingüísticos, visuales y auditivos

3.3. Análisis negativo en profundidad

4. Punto(s) de vista encajados, audiencias inferidas y propósitos

4.1. Análisis de puntos de vista y construcción de personajes

4.2. Análisis de las audiencias primarias y secundarias implicadas o pretendidas

4.3. Análisis de propósitos y objetivos encajados 
5. Análisis de la organización dinámica de información y estrategias de disposición espacial

5.1. Organización dinámica, opciones y limitantes estructurales y de navegación

5.2. Análisis de las estrategias de toma de decisiones y de las herramientas de accesos

5.3. Análisis de los elementos interactivos e hipervínculos externos

5.4. Análisis de los hipervínculos externos

6. Análisis contextual, procedencia e inferencia

6.4.1. Identificación de fuentes y generadores de información

6.4.2. Plataformas tecnológicas, sus implicaciones y limitaciones

6.4.3. Atribución de hibridación cultural

El punto número 1, como indica el autor, es propiamente una fase previa al análisis y, de igual manera, en este texto la categorización y una descripción general de las impresiones y emociones han conformado el apartado número 3 del artículo. Hemos hecho un esfuerzo por vincular estas intuiciones y sensaciones más palpables y evidentes con ejes teóricos que nos permitan ingresar a las piezas con un horizonte de expectación acorde con el tipo de pieza que analizamos y teniendo como antecedentes interpretativos los propios textos de Sharon Daniel al respecto. Aun cuando la misma creadora ha formulado textos en los que reflexiona sobre su quehacer artístico, nos parece que la explicitación del uso de las imágenes y los recursos visuales no han sido explorados de manera tan profunda como aspiramos a hacerlo aquí.

Continuando con el análisis, y en lo referente al inventario de características sobresalientes y tópicos (punto número 2), desde la propia descripción de las piezas en los abstract proporcionados por Daniel, hasta la experiencia de navegación de los dos sitios web, podemos constatar que se trata de un repositorio de grabaciones de entrevistas en audio. No hay registro en video, sólo sonoro. De alguna forma se hace evidente el punto 2.4 que sugiere Pauwels, el del análisis negativo. La ausencia de video de las entrevistas se vuelve un elemento palpable que determina toda la experiencia de navegación. Lo que automáticamente nos hace preguntarnos cómo es que la imagen del cuadro de entrevista (la cabeza parlante) es sustituida para generar una experiencia multimedia.

Lo que encontramos son, en el caso de Public Secrets, viñetas o recuadros con textos (casi como si fueran post-its con pequeños extractos de las entrevistas) que, al pasar el cursor del ratón revelan que al hacer clic se puede también escuchar el mismo texto. Para el caso de Blood Sugar la representación visual del audio de las entrevistas es un poco más sofisticado, pues lo que encontramos son soundwa- 
ves, una representación visual de la onda sonora completa de la entrevista. Esta imagen es una representación visual creada como si fuera parte por un programa de computadora para editar audio. Esta onda de sonido es lo que un programa mostraría en la pantalla a quien estuviera editando o montando sonidos.

Figuras 1 y 2. Despliegue visual de Public Secrets y Blood Sugar, respectivamente
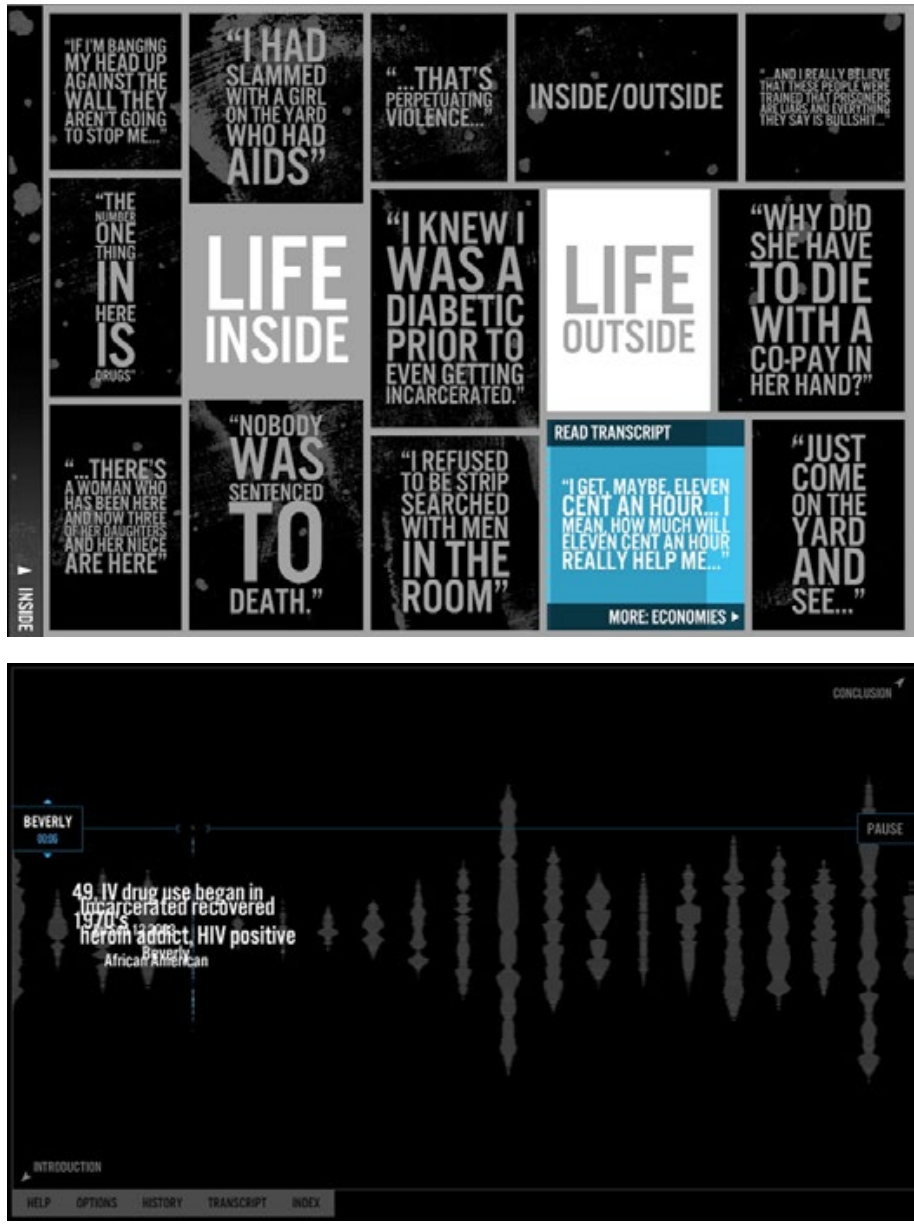

Fuentes: Public Secrets y Blood Sugar. 
En ambos casos y viendo las dos capturas de pantalla de las figura 1 y 2 , podemos extraer algunos de los tópicos generales de las piezas. Digamos que los campos semánticos son fácilmente reconocibles en ambas. Conceptos o frases como «sentencia de muerte», «vida adentro», «perpetuación de la violencia», «VIH positivo», «afroamericano», «encarcelamiento», «adicto a la heroína» aparecen en el primer vistazo.

La forma de interacción con la interfaz es que al hacer clic sobre los recuadros o sobre las ondas sonoras se despliega el audio correspondiente. En casi todos los casos, también las transcripciones en texto están disponibles, lo que aumenta las relaciones intramodales.

En el caso de Public Secrets hay tres partes generales, o pestañas de contenido, divididas a su vez en dos partes u opuestos. Los opuestos que aparecen son: adentro/afuera; vida desnuda/vida humana y secretos públicos/utopía. Cada concepto general despliega un tablero de textos como el que vemos en la figura 1. Es una interacción por bloques simples que se van agotando y que es, relativamente fácil notar cuando hemos sido exhaustivos en escuchar cada categoría o pestaña.

En el caso de Blood Sugar, la interfaz es un poco más sofisticada. Al dar clic a la onda de sonido, se hace un acercamiento (zoom) a la onda que hace desaparecer el resto de las ondas (correspondientes a las entrevistas del resto de personajes). La onda sonora es parte de una animación conocida como nube de conceptos que funciona a través de textos que se mueven como si flotaran y que cambian de dirección conforme se mueve el cursor del ratón. Además, una línea recorre la onda sonora, mostrando la progresión o avance del audio. Conforme avanza y el comentario va diciendo palabras clave, éstas van apareciendo en la pantalla. Cada palabra que aparece es susceptible de hacerle clic y desplegar un hipervínculo. Y las palabras, al ser parte de temas comunes, se repiten en las entrevistas de varios de los personajes, por lo que al dar clic a un fragmento o frase, pueden aparecer los nombres del resto de personas. Si se da clic al nombre, saltamos a la onda de sonido correspondiente a su entrevista. La sensación es de ir penetrando en la conversación y la inmersión, aumenta. Es como si fuéramos haciendo zoom o acercamientos hacia el interior de la plática y de la verdad del personaje. Y, en el último nivel, el último acercamiento, entramos a un gráfico animado de una célula y sus partes.

El último nivel, el gráfico de la célula se corresponde con el concepto que faltaba introducir de la sinopsis que Sharon Daniel hace sobre su pieza: la investigación biológica. El abuso de drogas inyectables tiene una dimensión física vinculada con la salud personal y la salud pública. La metáfora biológica visual es el sustrato profundo de la propuesta de Daniel donde se junta el funcionamiento corporal y el sistema carcelario y el de salud pública. Es una pieza que formula una poderosa argumentación sobre cómo pensar la marginación de los adictos desde una perspectiva biopolítica. 
Figuras 3, 4 y 5. Niveles de acercamiento, visualización de la nube de palabras y el gráfico de la célula
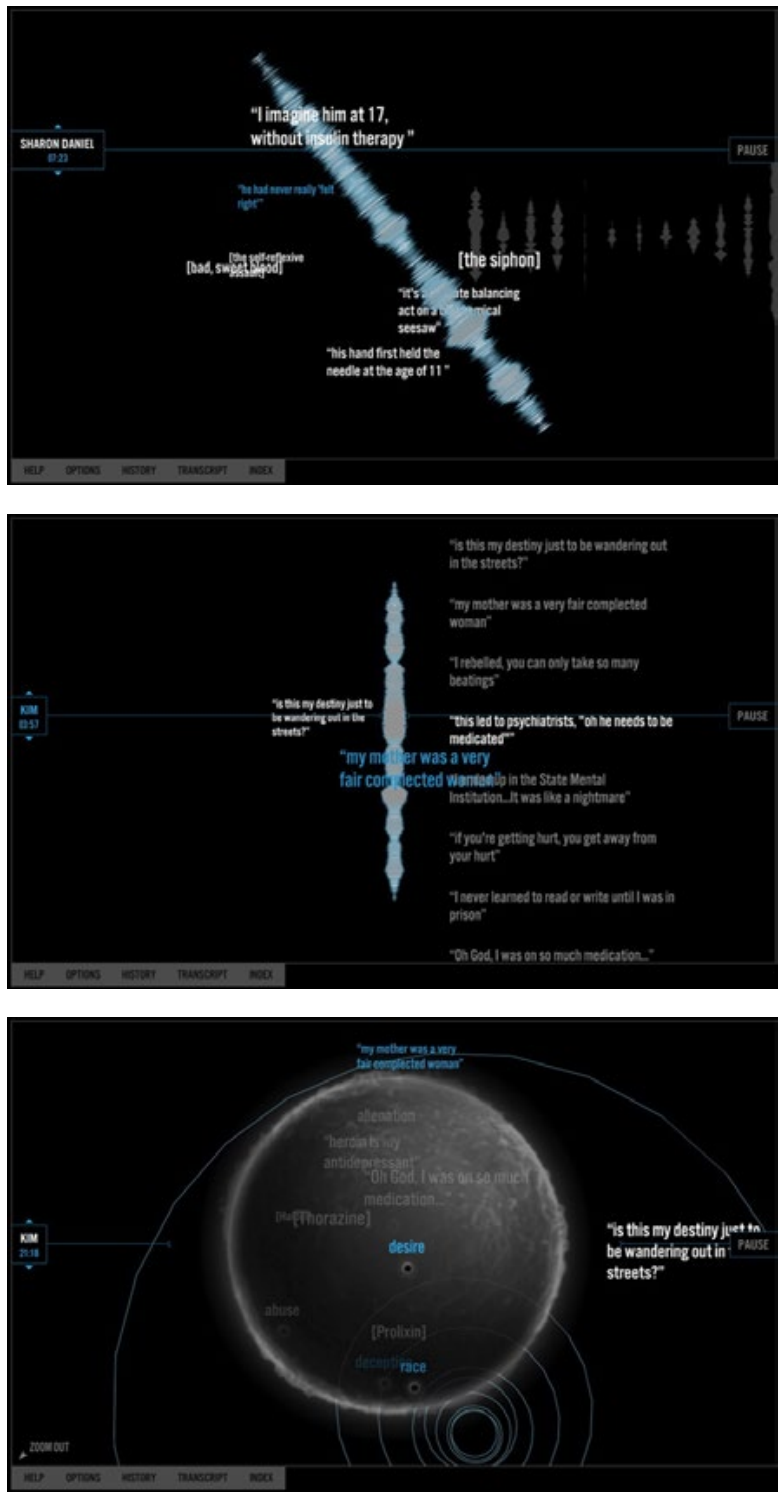

Fuente: Blood Sugar. 
La sensación de estar dentro de un sistema interconectado, flotante, cambiante hace que la sensación de inmersividad sea poderosa. Lo que va aparejado con una dificultad para notar si hemos sido exhaustivos en escuchar y dar clic a cada palabra, frase o registro sonoro. La única manera de tener certeza que lo hemos recorrido todo es oír una entrevista después de la otra, sin hacer un solo clic. De este modo saltaremos de un personaje a otro. Esta posibilidad de recorrer por individuo (por nombre) es imposible en Public Secrets.

El siguiente punto (número 3) que corresponde al análisis profundo del contenido excede los objetivos de este texto. Implicaría conocer cada declaración, fragmento o comentario de cada entrevistado, hacer una lista pormenorizada de los textos y gráficos, así como todas las imágenes y animaciones; conocer todas las tipografías, tamaños de letra y los colores utilizados para cada texto, onda sonora o registro de audio. Y luego pasaríamos a la programación, los niveles generados para la experiencia del usuario y las rutas de navegación posibles hasta tener un mapa detallado de las posibles tomas de decisión de quien visite los sitios. Esta transcripción requeriría una publicación mucho más extensa que, consideramos, no es necesaria para sostener los argumentos hasta ahora presentados respecto de las categorías de análisis que articulan este texto.

De algún modo, la fase número 4 sobre los puntos de vista y la construcción de personajes es el corazón del propósito de las piezas. La diversificación de voces, la creación de estas experiencias corales, polifónicas, interconectadas, aportan la sensación de que la experiencia de la cárcel, la adicción o la marginación, están encarnadas en individuos únicos. La sensación o idea que genera la inmersión en los sitios web es la de estar asistiendo a un colectivo que habita al interior de un sistema. También por eso son sitios de internet creados de forma hermética o cerrada. No tiene vínculos al exterior (fase 5 del modelo), pues pretende generar una narrativa o experiencia claustrofóbica, opresiva (enfatizada por la dominancia del color negro en ambas piezas), para que el navegante empatice con los entrevistados. La relación de poder que Sharon Daniel intenta hacer que emerja es la del sistema económico y legal con los individuos marginados o excluidos, drogadictos y presos. $\mathrm{Y}$ aquí es donde el camino que recorríamos, desde el testimonio como principio teórico y que nos llevaría hasta la creación de una comunidad como conclusión, termina. Las declaraciones obtenidas por Daniel en las distintas instituciones carcelarias y de asistencia médica y social forman un corpus de experiencias y relatos sobre los temas que le interesa abordar. Retomando la definición que aportábamos sobre el testimonio, su función de la búsqueda de justicia o de evitar que los eventos trágicos se repitan cobran sentido al interior de Public Secrets y Blood Sugar. Los tableros de declaraciones o las nubes de entrevistas, en un caso y el otro, son elementos documentales que funcionan por acumulación, evita la indexación visual de la realidad por cuadros de entrevista y los sustituye con otros recursos para potenciar el sonido y la visualización gráfica como mecanismos de interacción. 
Al final, al ingresar y sumergirnos en ambas piezas, el desbordamiento emocional y conceptual sucede por ir saltando por las descripciones explícitas de la experiencia carcelaria o por los procesos de deterioro y marginación de los adictos a las drogas inyectables dentro de sitios web herméticos que sólo nos llevan de una declaración a otra, donde los temas y conceptos son repetidos, reversionados, complementados. Un bucle, un laberinto inexpugnable que sólo nos invita a perdernos sin asegurar (ni permitir) que escapemos de ellos. Y, aunque Blood Sugar tiene una pequeña conclusión, en realidad es más como un argumento final que nos da un posible pretexto para salir de la experiencia.

Estos dos documentales web no utilizan tampoco recursos en la plataforma para indicarnos la duración aproximada de la experiencia, por lo que su vocación es inmersiva. Pretende que avancemos en la interfaz a través de ir completando declaraciones de manera progresiva, sin filtros, ni estructura narrativa. Nunca tenemos noción de que haya una evolución dramática que intuya un final, un cierre, deambulamos dando tumbos por las animaciones, cuadros de texto, ventanas emergentes o acercamientos. La sensación de no poder salir, nos obliga a voluntariamente abandonar la web sin dar por terminada la reflexión. No tenemos una conclusión argumentativa, no llegamos a construir una clausura, debemos formularla al dejar de navegar y abandonar al grupo que nos ha confiado y confesado sus vidas y experiencias. Salir es la manera en que nosotros, a través de la separación de la pantalla, debemos conscientemente reencarnarnos en nosotros mismos con todo lo que hemos oído y visto de esos otros que habitan en ambos sitios web. Así es como pasamos de la empatía a la reflexión crítica. El espacio cerrado de la inmersión debe ser roto, perforado por nuestra decisión de salir y es ahí donde nos debemos preguntar si somos parte de esa comunidad, si nos hemos convertido en parte de quienes daremos testimonio de la exclusión y violencia que los sistemas económico y legal generan sobre las personas.

\section{Conclusiones}

En este ejercicio de análisis multimodal hemos buscado un corpus de estudio vinculado a la forma documental de base informática como es el documental web. El interés era encontrar piezas que tuvieran un componente artístico que hiciera de la expansión fílmica una propuesta interesante de contrastar con los mecanismos representacionales habituales; particularmente nos interesaba poner en duda el uso regular del registro realista de la entrevista. Por ello, el trabajo de Sharon Daniel nos parece relevante y fértil de analizar.

Como ha demostrado el despliegue de los recursos visuales utilizados por Daniel, al omitir el busto parlante de los entrevistados como recurso representacional nos impele a buscar otras formas de vincular imágenes, gráficos, animaciones y textos con los relatos registrados en audio. Este desplazamiento del régimen visual como 
privilegiado para construir el testimonio y la relación del cuerpo del testigo con las tecnologías de registro hace que las piezas de Daniel sigan la propuesta de Jessica Silbey de recuperar la confianza en el testimonio oral de quienes han presenciado un acontecimiento y aprender a dudar o sospechar de los sesgos naturalistas de la imagen; mucho más si están asociados a la grabación en contextos legales o periciales. Esta suspensión de la credulidad del régimen escópico es también, en automático, un mecanismo que nos hace preguntarnos por cómo el sistema utiliza estas imágenes o grabaciones como métodos de exclusión y violencia contra los individuos. Daniel echa luz a esta tensión y logra que los testimonios sonoros, con sus complementos visuales, nos hagan evidente el fin último de estos registros sobre los hechos del pasado: intentar que las tragedias, atrocidades y sufrimientos no vuelvan a suceder.

También hemos mostrado cómo es que, a través del desdibujamiento de los individuos por no usar sus imágenes, sus cuerpos, Sharon Daniel crea una materialidad audiovisual e interactiva que promueve pensarlos como grupo, como colectivo, como un coro polifónico que nos hace sumergirnos en el tema sin dejarnos desbordar emocionalmente por la identificación con una persona. Nos empuja a tener que conectar unos audios con otros, unas experiencias con otras, unas personas con otras. Este ejercicio de conexión es el que eleva el estatus del testimonio como herramienta de creación de comunidad, lo que hace florecer la dimensión política de las piezas.

No podemos dejar de evidenciar que la riqueza de estos dos documentales web posibilitan un análisis multimodal mucho más detallado, que pueda mostrar muchos más matices, comentarios y tópicos vinculados a la justicia social y la exclusión, temas predilectos de la reflexión artística de Sharon Daniel. Intentaremos en un nuevo proyecto editorial subsanar la superficialidad de este esfuerzo. Pero estamos seguros que estos vacíos que el análisis ha dejado también son un llamado al lector para que visite los sitios y explore estas experiencias interactivas.

Podemos concluir diciendo, en general, las formas interactivas del documental plantean, por el simple hecho de transformar la pantalla de proyección fílmica o videográfica en una pantalla de computadora, o en un espacio intervenido con interfaces físicas, nuevas formas de entender las relaciones del cuerpo con las tecnologías de representación de la realidad. El documental web aporta un territorio vasto y útil para pensar cómo las interfaces están ingresando y modificando nuestras formas de entender el mundo y mediar nuestras relaciones con los demás y con nuestro entorno.

\section{Referencias}

Bakir, Vian (2010). Sousveillance, Media and Strategic Political Communication. Iraq, USA, UK. Nueva York: Continuum. 
Bateman, John; Wildfeuer, Janina; Hippala, Tuomo (2017). Multimodality. Foundations, Research and Analysis, a Problem-oriented Introduction. Berlín: Walter de Gruyter GmbH.

Bruzzi, Stella (2016). Narrative, "Evidence Vérité," and the Different Truths of the Modern Trial Documentary. En: Balsom, Erika; Peleg, Hila (eds.). Documentary Across Disciplines. Cambridge: Haus der Kulturen der Welt/MIT Press.

Comolli, Jean-Louis (2007). Ver y poder. La inocencia perdida: cine, televisión, ficción, documental. Buenos Aires: Aurelia Rivera/Nueva librería.

Daniel, Sharon (2012). On politics and aesthetics: A case study of 'Public Secrets? And 'Blood Sugar?. En: Studies in Documentary Film, vol. 6, $\mathrm{n}^{\circ}$ 2. Bristol: Intellect, 215-227.

Kress, Gunther R. (2010). Multimodality. A Social Semiotic Approach to Contemporary Communication. Londres: Routledge.

Nichols, Bill (1997). La representación de la realidad. Barcelona, Paidós.

Pauwels, Luc (2011). Researching Websites as Social and Cultural Expressions: Methodological Predicaments and a Multimodal Model for Analysis. En: Margolis, Eric y Pauwels, Luc (eds.). The SAGE Handbook of Visual Research Methods. Londres: SAGE.

Silbey, Jessica (2010). Evidence Verite and the Law of Film. En: Cardozo Law Review, $\mathrm{n}^{\circ}$ 31. Nueva York: Cardozo School of Law, 1257-1299.

Torchin, Leshu (2012). Creating the Witness. Documenting Genocide on Film, Video, and the Internet. Minnesota: Minnesota University Press. 